\title{
Efficiency of public-private co-regulation in the food sector: the French voluntary agreements for nutritional improvements ${ }^{\text {is }}$, 论许
}

\author{
Clementina Sebillotte* \\ INRA, UR1303 ALISS, 94205 Ivry-sur-Seine, France
}

Reçu le 7 février 2019 - Accepté le 11 juin 2019

\begin{abstract}
This article analyzes co-regulation as a policy instrument that makes it possible to achieve synergy between public support and private efforts in the food sector to improve the nutritional quality of the food offer. Our objective is to demonstrate the interest and the limits, as well as the conditions of the efficiency of this instrument, through the empirical analysis of the French voluntary agreements for nutritional improvements (charters) implemented in the framework of the French National Nutrition and Health Program (PNNS). We propose an interpretative model of the policy action on the nutritional quality of the food offer set out in the PNNS and we carry out new indicators of success to assess the efficiency of voluntary agreements in the food sector.
\end{abstract}

Keywords: voluntary agreements / nutrition policy / co-regulation / voluntary commitments / nutrition quality

\begin{abstract}
Résumé - Efficience de la co-régulation publique-privée dans le secteur de l'alimentation: les accords volontaires français pour l'amélioration nutritionnelle. Cet article analyse la co-régulation en tant qu'instrument politique permettant de réaliser une synergie entre les initiatives publiques et les efforts privés dans le secteur alimentaire pour améliorer la qualité nutritionnelle de l'offre alimentaire. Notre objectif est de démontrer l'intérêt et les limites, ainsi que les conditions d'efficience de cet instrument, à travers l'analyse empirique des accords volontaires français d'amélioration nutritionnelle (chartes) mis en place dans le cadre du Programme National Nutrition et Santé. (PNNS). Nous proposons un modèle interprétatif de l'action politique sur la qualité nutritionnelle de l'offre alimentaire définie dans le PNNS et nous présentons de nouveaux indicateurs de succès pour évaluer l'efficience des accords volontaires dans le secteur alimentaire.
\end{abstract}

Mots clés : accords volontaires / politique nutritionnelle / co-régulation / engagements volontaires / qualité nutritionnelle

\section{Introduction}

In industrialized countries, the imbalance between overly abundant dietary intake and the energy requirements of the population actively contributes to the determinism of noncommunicable chronic pathologies ${ }^{1}$ that are one of the major public health issues today (Hercberg and Tallec, 2000). Among these diseases, obesity and overweight are on the rise in

\footnotetext{
Contribution to the Topical Issue "Lipids and Health / Lipides et santé"

计 JEL categories: I18, D22

*Correspondance : clementina.sebillotte@inra.fr

${ }^{1}$ For example, cancer, cardio-vascular disease, osteoporosis, obesity, etc. Obesity itself is also one of the determining factors in the development of some diseases such as cardiovascular pathologies, type-2 diabetes, some cancers of the digestive system, etc.
}

industrialized countries as well as throughout the world, even if obesity and malnutrition co-exist in many developing countries.

When analyzing debates on anti-obesity policies, two main approaches, corresponding to two possible action levers, can be identified (Kersh and Morone, 2005; Kersh, 2009): targeting individuals and their behavior (eating habits, type of exercise they do) and/or targeting the environment (foods proposed, available exercise opportunities, urban planning, etc). Actions on the food demand and offer can be classified, respectively, according to these two levers.

Public and private sector efforts were traditionally concentrated on information policy (Golan and Unnevehr, 2008), assuming that the problem lies in consumer behavior and, therefore, the necessity to inform them about their choices (Kersh and Morone, 2005). However, an alternative vision of the problem gradually arose as a result of the development of diseases linked to diet: "many dietary choices are predetermined or influenced by market forces that are beyond the 
control of individual consumers" (Golan and Unnevehr, 2008). As of that time, it became obvious that the problem no longer depended on consumer decisions alone, but on the nutritional environment as well. "The underlying notion is that choices must be made, but the environment affects the content of choice." (Brownell et al., 2010).

In the last decades, food industry practices have been criticized as have been their products for contributing to a poor diet, leading to overweight and obesity (Kersh and Morone, 2002; Nestle, 2002; Brownell and Horgen, 2004; Ludwig and Nestle, 2008). In many countries, in recent years, we have seen the emergence of public initiatives aimed at modifying the nutritional quality of the offer, targeting product characteristics and sales outlets, marketing actions and advertising (JourdainMenninger and Lignot-Leloup, 2003). Some firms have implemented self-regulating policies to improve nutritional quality, these approaches are limited and their results are often mixed (Sharma et al., 2010). Some authors consider that the solution to chronic illnesses linked to diet partially lies in innovation in the food industry and would thus encourage partnerships between the private and public sectors (Yach et al., 2010). Voluntary agreements (VAs) are an example of these partnerships.

What are the underlying factors of the VAs performance to improve food offer nutritional quality? What indicators of success could be adequate to assess the efficiency of this kind of co-regulation in the food sector?

Our aim is to show the interest and the limits, as well as the conditions of the efficiency of VAs in the food sector, through empirical analysis of the French VAs for food nutritional quality improvements (hereafter referred to as charters). This policy device based on VAs, which we call the charter device, was launched by the French government in 2007 within the framework of the French National Nutrition and Health Program established in 2001.

This policy action is too often judged on the sole criterion of the number of agreements signed, so we established performance indicators to build our own evaluation of the device and of the charter approach. Our analysis deals with two key dimensions of the modification of the offer by voluntary commitments: the intrinsic quality of the commitments and the part of the overall offer covered by the signed agreements. It raises an essential question in terms of VAs concerning the food offer: should the policies attempt to minimally improve a large part of the offer or, instead, try to obtain a radical improvement that may only involve a small part of it, hoping that the rest of the offer will follow as a result of competition (on nutritional characteristics) between the economic actors? In other words, how can we reconcile the requirement for nutritional quality level improvement imposed on the economic actors with the adhesion commitment level?

After dedicating section 2 to materials and methods, we describe the theoretical background and the practical context of our question in section 3. In section 4, we propose an interpretative model of the policy action on the food offer nutritional quality set out in the PNNS, we focus on the French charter device and the way it operates and we analyze the profile of the signed charters. Then, we propose new indicators to assess the efficiency of VAs in the food sector. Before drawing the conclusions, we identify the limits of this policy action on the offer, we discuss the charter dilemma, dealing with requirements and adhesion level, and finally put forward charter device reasoning in terms of dynamic trajectory.

\section{Materials and methods}

Our longitudinal qualitative analysis (Pettigrew, 1990) is based on the interview method (Romelaer, 2005; Kvale and Brinkmann, 2009), the analysis of documents and note-taking in the field. We studied the empirical cases of six economic operators (EOs) who had signed the voluntary charters: Nestlé, Paul, Casino, Bleu-Blanc-Cœur, Unijus and FiacAdepale Fruit Section. Additionally, we interviewed representatives of individual firms or groups of firms, who signed (Danone, Unilever, Bongrain, Fict...) or did not sign (Edenred, Franprix-Leader Price) charters as well as public actors (people in charge of PNNS, ministry officials, scientific researchers, scholars...).

We analyzed two types of data obtained between 2007 and 2012. The first type concerns primary data gathered from (i) thirty 2-3 hour interviews, recorded and transcribed, with actors mandated by the government who participated in these nutritional policy actions, public and private food and nutrition experts, actors from industry, the mass market sector, professional and syndicated food associations, etc.; and (ii) public presentations, working group meetings in which we participated (mainly within the Lipids' group managed by the Ministry of Agriculture), informal discussions, etc. The second type deals with secondary data taken from written sources (particularly the texts of agreements that were signed and made public, as well as private and public documents, news articles and research papers) and audiovisual documents (presentations, interviews conducted by third parties). We crisscross these different documents in order to identify processes and state variables according to the SYSPAHMM method ${ }^{2}$ (Sebillotte and Sebillotte, 2002, 2010). These processes and state variables, that can be assimilated to the "meaning units" produced by the coding methods (Allard-Poesi, 2011; Ayache and Dumez, 2011), are organized into groups or categories; each process or state variable can belong to more than one category. They are inventoried into a database for organizing, comparing and ranking such as "ways of conceptualizing data that then generated new insights (...) for further exploration" (Rossman and Rallis, 1998). Following Rossman and Rallis

\footnotetext{
${ }^{2}$ The SYSPAHMM is a foresight method particularly suitable for research which allows traceability, uses mathematical processing and gives the possibility to test the "regularity" of our work. SYSPAHMM method comprises several stages: first it produces a static graphic description of the study system, second identifies processes and state variables, next transforms the most important processes into hypotheses, after that establishes a matrix of influences of each hypothesis on the others, then breaks down these hypotheses into clusters of hypotheses that are more closely linked together, finally builds microscenario families based on relationships between hypothesis within the cluster and constructs macroscenarios. In this paper, we mobilized the second stage of the foresight SYSPAHMM method in handling primary and secondary data to identify short sentences called "process" in order to describe what happens and what actors do. We complete this dynamic description with state variables that allow us to quantify processes at work.
} 
(1998) "writing about qualitative data cannot be separated from the analytic process". Therefore we integrated the intermediary findings progressively into the subsequent versions of the monographic texts; these texts allowed us to supply longitudinal study (Forgues and Vandangeon-Derumez, 2007) and formalize progressively our interpretation of the French model for policy action on the food offer.

\section{Theoretical background and practical context}

\subsection{Public intervention on the food offer: a promising avenue for public health}

Scientific studies concerning policy interventions, aimed at creating an environment favorable to physical activity and healthy diet, present promising results (Basdevant et al., 2006). Among these studies, some focus on modifications of food composition in order to modify the nutritional quality of the offer, and on their impacts in terms of public health.

At the end of the 1990s, some scientific studies had already shown the positive effects of modifying the quality of the offer on public health (Swinburn et al., 1999). More recent studies have revealed the beneficial effects of public and private strategies leading to modifications of the composition of foods in order to improve the quality of the offer. These analyses are particularly focused on the decrease of salt content (Girgis et al., 2003; Thomson, 2009) and trans fatty acids (Saunders et al., 2008; Unnevehr and Jagmanaite, 2008; L'Abbe et al., 2009; Ratnayake et al., 2009; Ricciuto et al., 2009) and the increase in fiber content (Mancino et al., 2008).

Combris et al. (2011) simulated the effects in France of an improvement in the content of the major macronutrients in some food categories. They observed a wide variability of nutritional quality within each food category. Moreover, it appeared that products with lower nutritional quality would lead to large modifications in the quantity of nutrients on the market and, as a result, to changes in the level of nutrients consumed by individuals. The simulations produced by this study suggest potential positive effects in terms of public health of an intervention on the offer based on the reformulation of the content of several macronutrients, which would not significantly affect taste or production costs.

\subsection{Co-regulation for modifying the food offer}

Three ways to regulate the food offer found in the literature aim at directly improving the nutritional quality of foods by modifying their composition. They include direct regulation or "command and control regulation" (Girgis et al., 2003; Eckel et al., 2007; Unnevehr and Jagmanaite, 2008), self-regulation (Seiders and Petty, 2004; Lang, 2006; Hawkes, 2007; Pomeranz and Brownell, 2008; Harris et al., 2009; Pomeranz et al., 2009; Stanley and Daube, 2009; Wilde, 2009; Sharma et al., 2010) and co-regulation between public and private actors (Sebillotte, 2016). Within a co-regulation approach, the government gives firms the right to play a legitimate role in the improvement of public health. At the same time, the government, through its supervisory structure, gives itself the right to guide and control firms' actions when they attempt to solve social problems. This makes it possible to reconcile the mobilization of economic operators (EOs) relevant knowledge with compliance with public rules. VAs belong to this latter category.

\subsection{Voluntary agreements: the efficiency of dynamic and interactive policy process}

Starting from 1970s, in France, Lascoumes et al. (1989) identifie a large number of VAs but it is in the mid 1980s that the voluntary approaches flourish in environmental management and regulation (Grolleau et al., 2004). Less explored than other public regulation instruments, the voluntary approaches in the field of environment were studied from economic perspective (David, 2004; Grolleau et al., 2004; Mzoughi, 2005) and also from the point of view of management sciences (Aggeri, 1998, 1999), sociology (Lascoumes et al., 1989; Lascoumes, 1994) and legal sciences (Hervé-Fournereau, 2008). Under varied labels, like branch agreement, branch program, anti-pollution sector plan, etc., these regulation instruments cover diverse realities (Highley et al., 2001; Grolleau et al., 2004). And beyond that diversity, three common criteria are displayed by the majority of voluntary approaches (Grolleau et al., 2004; Hervé-Fournereau, 2008): the voluntary engagement character of regulated entity; the objective to improve the environment performance goes beyond reglementary conformity; the improvement of the economic efficiency allows "achieving a social goal at the lowest cost or with attractive private benefits" (Grolleau et al., 2004). The definitional characteristics of VAs put forward by authors such as Aggeri (1999) are:

- "the preeminence of a horizontal cooperative process in which firms are partners";

- "the signing of a contract (convention, charter, VA, etc.) ratifying the agreement between the two parties and describing their reciprocal commitments";

- "a monitoring process involving various resources (norms, instruments, essays, reports, etc.)" (Aggeri, 1999).

Even if European Commission considers that not all VAs implemented were successful, it encouraged their implementation (EC, 1996, 2002) while suggesting some actions to improve their efficiency and effectiveness: prior consultation with the parties involved and formalization of technical and administrative conditions of VAs (formal contract, quantitative targets according with a predefined schedule, obligation of each part must be laid down, monitoring modalities, regular publication and public availability of the outcomes) (EC, 1996).

The debates on the environmental VAs efficiency lie in: the ambition level and the socially satisfying character of the collective targets; the question of compliance given their nonmandatory status; their cost-efficiency, compared to other possible policy instruments (economic instruments and direct regulation) (Glachant, 1995). The economic analysis of the VAs focuses on the intense phase of negotiation between the authorities and firms, at the end of which the collective VAs are signed. In some cases, high demand for time and resources that negotiation requires from stakeholders is seen as a source of inefficiency for VAs (Coglianese, 2001; Grolleau et al., 2004). 
VAs efficiency analysis shows that in case of i) lack of knowledge and ii) insufficiently dissuasive means to sanction, the authorities can negotiate the technical solutions cost disclosure and their implementation with private actors. From that viewpoint, the VAs are considered a default solution which can put the authorities at risk of regulatory capture by the private interest to the detriment of the public interest. By contrast, according to Aggeri (1999) in the "situations of great uncertainty, involving long periods of time and involving the wide range of actors", when neither the public authorities nor firms have enough knowledge and means to solve issues, the regulatory process cannot be considered as "the result of pressure and negotiations between defined actors or interest groups with clearly defined strategies" (Aggeri, 1999). If we consider the specific nature of the addressed problem, its complexity and its temporality and take into account learning and innovation processes in which many involved stakeholders are concerned by the public policy objectives (Aggeri, 1999), the conditions for the efficiency of VAs change and, consequently, the way in which they are evaluated.

For example, the efficiency of a VA cannot be evaluated in the same way as if the solutions and/or their effects are known to the operators, or as if the solutions are to be designed as part of the VA and subsequently applied. If in the first case the evaluation of VAs can focus on the efficiency of the negotiation, in the second case it is a question of evaluating and coordinating processes spread over time, contributions to the solution distributed between several actors and solutions that still need to be tested in the field.

Given i) the wide variety of products and processes that characterize the food supply, ii) the diversity and the large number of actors involved in food supply and demand, iii) the uncertainties that characterize the process of political intervention on food and nutritional issues (evolution of nutritional knowledge, reactions of actors to policy actions, attribution and distribution of responsibilities between the actors concerned...) (Sebillotte, 2016), our analysis of the PNNS VAs efficiency cannot be satisfied with the only static interpretation of public policy and requires to consider public action as a dynamic and interactive process. In this framework, it would be more appropriate to speak of "procedural efficiency" (Aggeri, 1999).

\subsection{The French voluntary charter device ${ }^{3}$ for nutritional improvement}

In France, the possibility offered to $\mathrm{EOs}^{4}$ in the food sector ${ }^{5}$ to sign VAs with the government, known as "charters of

\footnotetext{
${ }^{3}$ In this article, the word device translates the French term "dispositif" that we use in the same meaning of Foucault's thought (Foucault, 1977).

${ }^{4}$ These EOs may be firms that produce, process or distribute food for human consumption or feed for animals. The committee responsible for drawing up the reference model used the definition of a food sector firm given in EC regulation no. 178/2002.

${ }^{5}$ They may belong to the agro-food industry, the retail sector, the mass catering sector or the agricultural production sector. They may also be a brand distributor or a professional or interprofessional organization or association (EC regulation no. 178/2002).
}

voluntary commitments for nutritional improvement", is one of the key actions launched in 2007 within the framework of the PNNS (Box 1).

\section{Box 1. French National Nutrition and Health Program}

The French National Nutrition and Health Program (PNNS) was implemented in December 2000. It is coordinated by the Ministry of Health, in conjunction with government authorities responsible for agriculture and fisheries, consumption, youth and sports, national education and research. This policy acts simultaneously on the food demand and on the food product offer. In its first phase, the PNNS (2001-2005) mainly focused on actions concerning information, orientation and education of the consumer in order to develop balanced dietary behavior and adapted physical activity, and to produce consumer recommendations, while the objectives concerning the offer remained just words rather than being translated into tangible actions. In the second phase, PNNS2 (20062010), actions related to the demand continued (campaigns to promote and disseminate nutritional recommendations for consumers, nutritional education in schools, etc.), whereas actions concerning the offer became effective, particularly through the French collective and individual voluntary charter device. Actions concerning the offer and demand are continuing in the third and fourth phases, PNNS3 (2011-2015) et PNNS4 (2017-2021) respectively. For a description of the PNNS, the reader is referred to the work of Hercberg et al. (2008).

We present below the elements that make up the charter device and its operation.

\subsubsection{Reference guideline and a committee responsible for charter validation}

To lay the operational groundwork for this action, an expert committee was empowered by the government to draw up a reference guideline capable of helping operators in the food sector to establish charters. This guideline also proposes orientations on possible means to be used for verification, validation and information about these commitments. A charter validation committee was constituted to examine and approve charter proposals on behalf of the government.

The reference guideline stipulates that these charters can be assigned to only one EO (individual charter) or to a collective EO (collective charter).

\subsubsection{Charters for nutritional improvement}

The aim of these charters is to improve the diets of the population in general, including disadvantaged populations. They therefore focus on the objectives defined by the PNNS for the population as a whole, on the consumption of salt and simple sugars, total lipids, saturated fatty acids, complex carbohydrates and fibers, and fruits and vegetables. The approach is progressive in that it is the effort that counts and not the level reached. Commitments concern both nutritional composition and portions recommended for consumption. The 
Table 1. Areas and sub-areas of intervention for PNNS charters.

\begin{tabular}{ll}
\hline \multicolumn{1}{c}{ Intervention area } & \multicolumn{1}{c}{ Intervention sub-area } \\
\hline Nutritional composition of existing products & $\begin{array}{l}\text { Nutritional characteristics, particularly modifications in the formulation aimed } \\
\text { at reducing the content of salt, simple added sugar and total lipids } \\
\text { Formulations other than those mentioned above } \\
\text { Drawing up menus }\end{array}$ \\
& $\begin{array}{l}\text { Development of alternative products } \\
\text { Creating alternative products }\end{array}$ \\
$\begin{array}{ll}\text { Product consumption (frequency, quantity, } \\
\text { target population) }\end{array}$ & $\begin{array}{l}\text { Increase in the consumption of fruits and vegetables } \\
\text { Organization of sales outlets } \\
\text { Development of communication and information at sales outlets and outside } \\
\text { of sales outlets } \\
\text { Marketing, advertising and sales promotion }\end{array}$ \\
& $\begin{array}{l}\text { External actions } \\
\text { Internal actions }\end{array}$ \\
\end{tabular}

Source: MAAP, MINEFI, MS 2007.

reference guideline recognizes four possible areas of intervention (Tab. 1).

These areas are not prioritized. Nevertheless, if there is no commitment in terms of nutritional composition, the applicant must give reasons for this. The validation of a charter is conditional on its significance, i.e., "that it covers a sufficient share of the applicant firm's products or a sufficiently large share of the profession represented by the organization that proposes the charter" 7 . Nutritional improvements that are the subject of commitments "must not affect the accessibility of products, particularly by an excessive increase in their prices" (MAAP et al., 2007). After discussion of each charter application, the validation committee issues its opinion on the proposed charter and decides whether or not to accept it. If the charter is not accepted, a letter will include the reasons and suggest the necessary modifications to be carried out by the applicant to submit once again.

As an incentive to commit, the government gives approved firms the possibility of making their commitment to a "nutritional improvement approach encouraged by the government" known to the public, according to a very precise procedure.

\subsubsection{Controlling compliance with commitments}

Commitment objectives must be precise, measurable, dated and controllable. The signatory to the charter must transmit the results of the annual assessment of his commitments to the validation committee and to the Food

\footnotetext{
${ }^{6}$ In general, at least two-thirds -in volume, in turnover or in promotional expenses - of the products, or two-thirds of the members in the case of a professional or interprofessional organization (MAAP et al., 2007).

${ }^{7}$ Two other conditions can be added to this condition for admissibility. One concerns the presentation of the charter in compliance with the pre-established reference guideline. The other deals with the establishment of a calendar with the dates when commitments will be completed.
}

Quality Observatory (Oqali). A charter can be modified at the request of the signatory economic actors or of the government. This flexibility and the absence of sanctions in the case of noncompliance with the commitments do not mean absence of control. The control indicators of each commitment, the means of verification of compliance with commitments as well as independent third parties responsible for carrying out this control are proposed by the EOs to the charter validation committee. Independent third parties are paid by signatory EOs, except for Oqali which is free of charge.

\subsubsection{Monitoring the impacts on offer quality by the Food Quality Observatory}

The government uses Oqali to monitor the global implementation of commitments and to assess their impact on the global food offer. This observatory was established in 2008 by the Ministries of Agriculture, Health and Consumption, and its implementation was entrusted to the French National Institute for Agricultural Research (INRA) and French Agency for Food Safety $(\mathrm{AFSSA})^{8}$, in partnership with professionals and consumer associations. For a description of the Oqali, the reader is referred to the work of Menard et al. (2011).

\subsubsection{Thematic working groups}

The charter device is completed by thematic (e.g. carbohydrates, lipids, salt) working groups that bring together a wide range of collective actors and partners (representatives of producers, manufacturers, retailers, mass catering actors, consumers, AFSSA, INRA, government agencies, etc.), coordinated by the Directorate General for Food of the French Ministry of Agriculture. Their aim is to contribute, through this collective endeavor, to building a reflection platform to develop charters, mainly collective, by the EOs. Their missions included:

\footnotetext{
${ }^{8}$ AFSSA became French Agency for Food Environmental and Occupational Health Safety (ANSES) in 2010.
} 

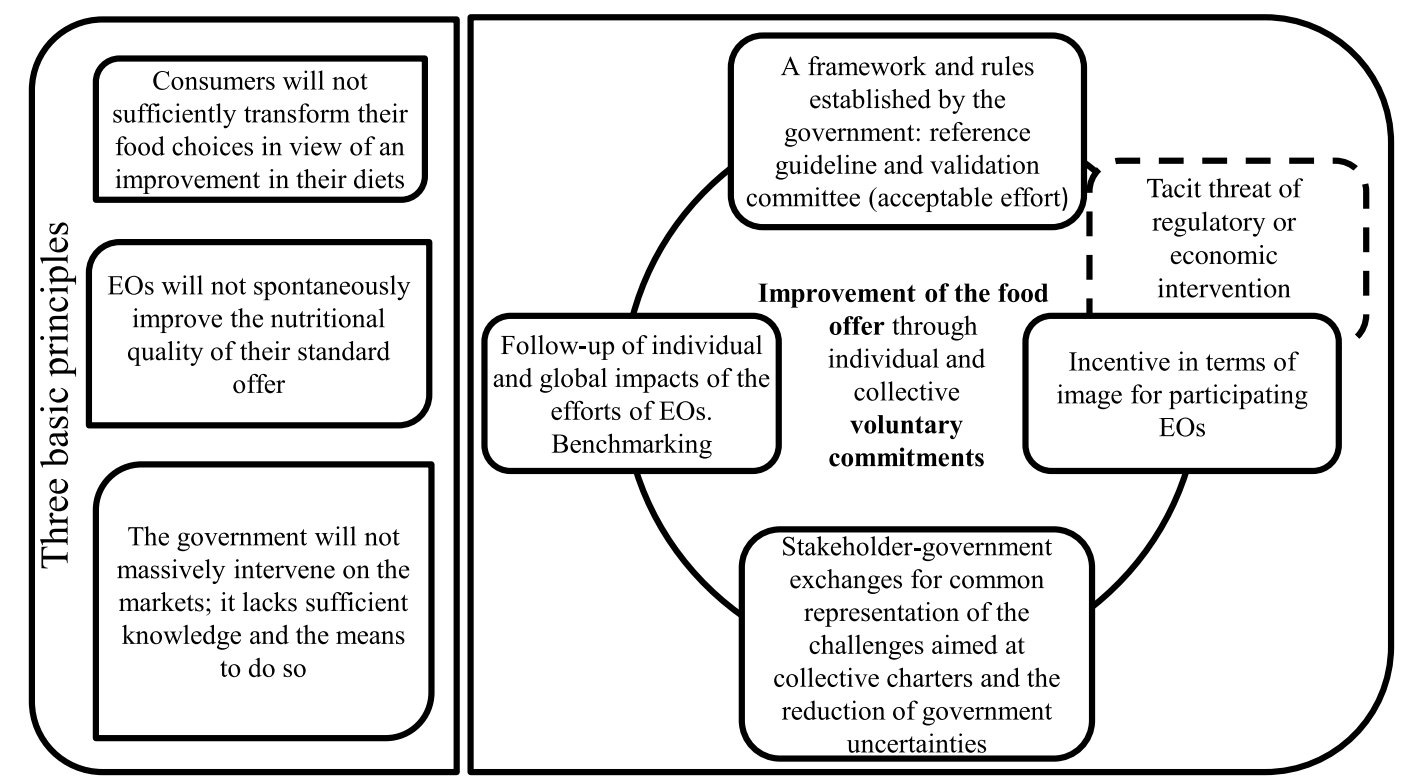

Fig. 1. Our interpretation of the French model for policy action on the nutritional quality of the food offer. Notes: EOs = economic operators.

establishing an accurate overview based on existing data in order to create a common knowledge base that is shared by all the participants; determining the range of possibilities for making nutritional improvements, given that the economic actors are subjected into specific constraints (technological, regulatory, organoleptic, economic, etc.); and identifying concrete actions to be implemented, particularly in the form of collective charters. For instance, the lipids group created in 2007 aimed at bringing together all the concerned actors who could examine food offer improvement possibilities with regard to lipids, sector by sector, and in line with the PNNS. On that account, the group has identified some improvement measures for lipid composition and food offer modalities (such as portion size, consumer product information, etc.) in all sectors. The group also analyzed these measures from the point of view of nutritional interest and anticipated its impact on food consumption and eating behaviors.

\section{Results and discussion}

\subsection{Our interpretation of the French model for policy action on the food offer}

According to our interpretation after analysis of the texts, interviews and official speeches, the model for policy action on the nutritional quality of the food offer (Fig. 1) designed by the French government is based on the following three general assumptions:

- consumers will not substantially transform their food choices in view of an improvement in their diets. Despite the measures implemented concerning the demand, their commitment is insufficient and remains so even if they are aware of nutritional recommendations;

- EOs will not spontaneously make nutritional improvements on the global offer in general and without affecting the accessibility of improved products. Self-regulation may be hindered by the fear of losing market shares. In fact, modifications implemented may alter the organoleptic quality and/or the costs of products, leading to price increases or the decrease in margins (Golan and Unnevehr, 2008). The public authorities consider that in order to improve the nutritional quality of the standard offer, in a general way and without changing its price (so that accessibility is not reduced), they most actively intervene to promote the participation of EOs;

- the government does not massively intervene in the markets: neither with an economic policy of taxing or subsidizing certain products; nor with a technical policy that would fix the standards that could perceptibly modify the characteristics of products on the markets (in terms of prices, organoleptic characteristics and nomenclature). The food sector is characterized by a wide diversity of products and processes. The government has neither sufficient knowledge to assess the possibilities of the evolution of companies (Aggeri et al., 1995) ${ }^{9}$ nor the means necessary to regulate and administer in these areas by classic instruments. It runs the risk of establishing measures that are unrealistic and, as a result, not followed (Barde, 1992). The government also expresses its intention of maintaining the variability of the food offer.

On the basis of these three assumptions and according to our interpretation, the French government designed an action model whose target is the nutritional improvement of the offer by means of voluntary commitments to nutritional improve-

\footnotetext{
${ }^{9}$ These authors show the importance of knowledge in the development of a regulation based on the definition of an "operational theory" of the regulation.
} 
ments, particularly collective ones. We propose a stylized representation of this model (Fig. 1):

- a framework and rules established by the government. The purpose of this framework is to encourage EOs (individually but especially collectively) to make commitments on nutritional improvements formalized by the signature of the VAs with the government. In addition, the government determines the rules with regard to the EOs: (i) by providing a structure for their actions in the form of a reference guideline to be adhered to; and (ii) by determining the acceptable level of effort proposed, without establishing it beforehand, but rather through the acceptance or rejection of commitment proposals made by the EOs;

- follow-up of the impacts from private efforts on the nutritional quality of the offer. This involves highlighting (i) the efforts of each signatory and their contribution to the improvement of the quality of the global offer, as well as ii) the impact of the overall charter device on the improvement of the offer. The aim of highlighting the impacts of private efforts is to create an emulation mechanism between firms;

- an incentive in terms of image for participating firms. In order to make the charter device more attractive, the government gives firms the possibility of making their commitment known to the public. They can therefore use their efforts towards nutritional improvement to boost their image. On the other hand, no coercive measure will be levied in the event of non-compliance with the commitments. The government did not officially formulate the threat of a future regulation. Nevertheless, the nutritional tax is always present, even in the background, in reflections and debates about nutritional policies. The contributions on drinks containing added sugars and on energy drinks, took effect in 2012 and 2013 respectively, served as a precedent that makes the tacit tax threat more credible;

- a common representation of stakes built by and with the concerned actors that allows the government to reduce its uncertainties. Finally, this model integrates forums of cross exchanges and learning (Hatchuel, 1994) between representatives of professional organizations, partners concerned by questions of nutrition and the government (e.g. voluntary thematic working groups, validation committee). Through these forums, the government provides itself with the means for its own learning process on nutrition-related issues. This knowledge could therefore be mobilized by the government in the future, to readjust the charter device over time, as well as to establish other means of intervention than those based on voluntary actions alone.

\subsection{Profile and characteristics of PNNS charters signed within the device}

From February 2007 to the end of 2012, that is, some six years after they were launched, 30 charters have been signed (MS and MES, 2012). Among the 30 charters, we can distinguish 26 individual charters, 24 of which were signed by manufacturers and two by distributors, plus four collective charters.
We can observe a strong predominance of individual compared to collective charters. The majority of the firms committed individually are involved in processing. The same is true for collective charters. The two distributors committed individually did so primarily as processors ${ }^{10}$, i.e., for the manufacturing of their retailer brands. In general, the agricultural production link is almost absent among the signatories. Retailers are poorly represented in terms of their core activity. This situation suggests that, because of this, the key to nutritional innovation in foods is in the processing link, and that contributions made at other levels of the sector do not appear to be decisive.

Among the individual charters, 11 were signed by major groups for one or several of their brands or firms (e.g., Danone for Taillefine, Nestlé for Herta, Maggi, Cereal Partners France and Produits de nutrition infantile ${ }^{11}$ in four different charters). Fifteen individual charters were signed by independent, generally large firms. Small and medium-sized firms were virtually absent. Within the signatories of four collective charters, three professional unions and a French non-profit association can be distinguished.

Among the collective charters, that of the Fruit Section of the Fiac-Adepale (processed fruits) was signed by firms that belong to the same level of the sector: processing. As for the charter signed by the Fict (cured meat products), in addition to the processors, there are two distributors since they belong to the union. Another situation is that of the Unijus (fruit juice) charter. It was signed by a fraction of the professional organization: fruit processors, packers, distributors and importers. Brokers or suppliers of raw materials were excluded because they would not play a major role in the evolution of market products. In contrast, for the Bleu-Blanc-Cœur charter, the signatory non-profit association (whose mission is to organize animal production that integrated nutritional concerns) is counting on the involvement of all of the actors of the food chain, from the linen producer to the final consumer. The four collective signatories all existed before the charter was signed, i.e., the members of the collective did not come together because they had the intention of presenting a common charter. Negotiations between collective members to arrive at a charter proposal were primarily focused on the level of improvement but not on the means necessary to achieve it. The member firms of the signatory collectives committed to issues that they could address with knowledge that they already possessed or that they were capable of producing themselves. The charters did not encourage exchanges of knowledge between firms, as was the case for the VAs in the automobile sector concerning the environment (Aggeri et al., 1995).

Only four charters propose commitments in the four eligible areas. All of the charters are committed to improvements in the area of nutritional composition (Tab. 2).

The texts of the charters and interviews with the EOs reveal that for some firms, nutritional improvement initiatives began long before the PNNS2 through more or less formalized actions. Companies like Unilever, Danone and Nestlé had

\footnotetext{
${ }^{10}$ Only one of the distributors, Casino, is commited in a distributor capacity, but only for an annual event for the "fruit and vegetable" department and for in-store nutritional balance awareness actions.

${ }^{11}$ Infant nutrition diversification products.
} 
C. Sebillotte : OCL 2019, 26, 34

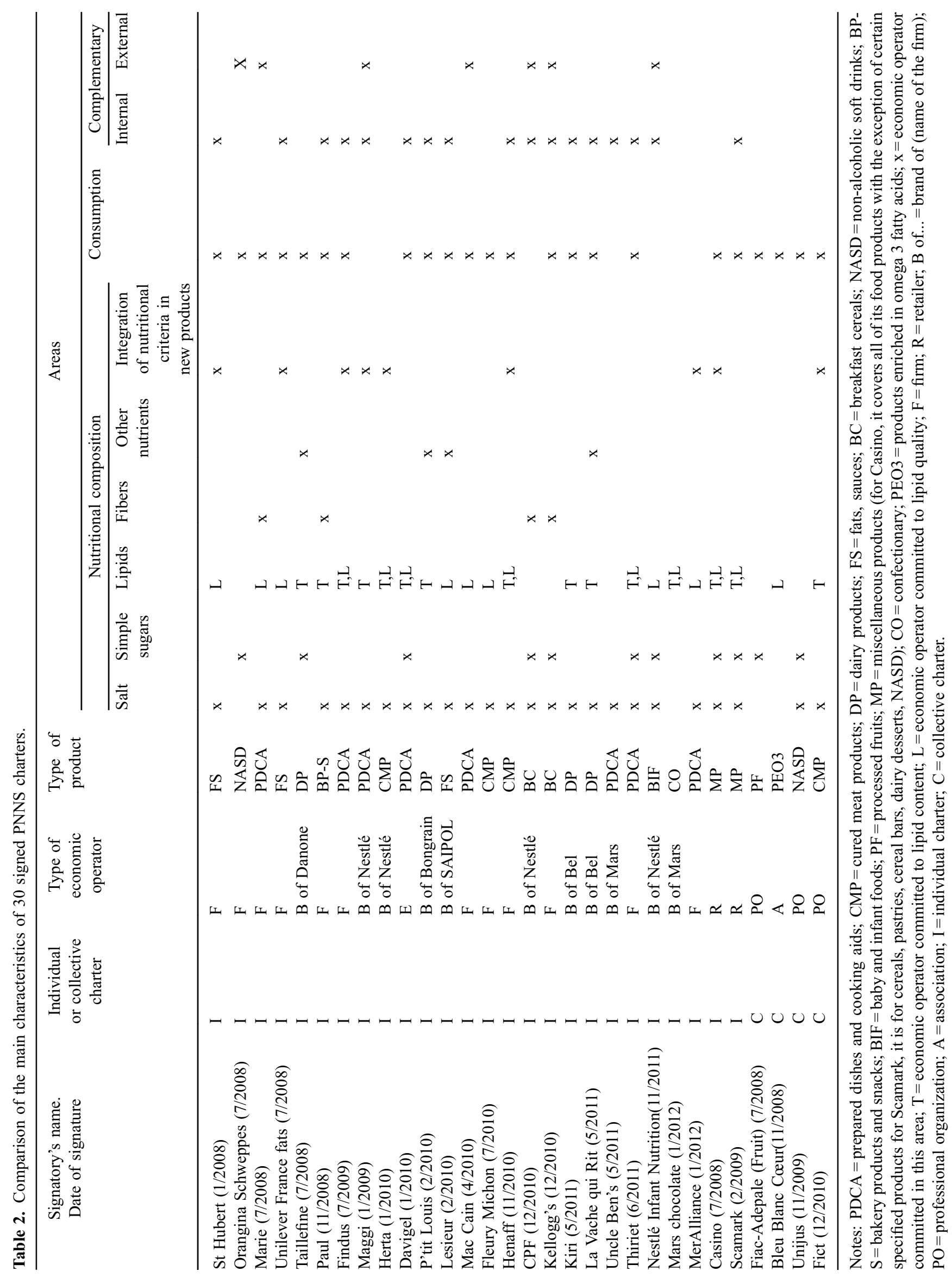


already undertaken nutritional improvement measures and created their own in-house nutritional quality reference guidelines. For example, Unilever established a nutrition enhancement program (NEP) (Nijman et al., 2006). For those companies that were already "initiated" to nutrition improvement, the charter device would only have strengthened or perhaps even legitimized their approaches. For other firms, the device may have played a role in triggering nutritional improvements or by encouraging the systematization of improvements carried out in an unsystemized way until then. Some signatories link their nutritional improvement approaches to environmental issues (e.g., Scamark) or to sustainable development (e.g., Casino) or corporate social responsibility approaches (e.g., McCain).

\subsection{Which assessment for the efficiency of the charter device?}

Different studies were carried out by Oqali to assess the direct impacts of the charters signed on the improvement of the quality of the offer. According to these studies individual efforts can be important but the impact of charters on the average nutritional quality of supply and on the nutritional intake of French consumers remains modest (Oqali, 2012, 2013). These results suggest an interest in the significant improvement of the composition of the offer.

External evaluation of PNNS2 was entrusted to the French General Inspectorate of Social Affairs (IGAS) and to the General Council on Food, Agriculture and Rural Areas (CGAAER). The voluntary commitment charters were qualified by this mission as an important action. Nevertheless, the results obtained were considered to be insufficient. In terms of the "methodology and the action philosophy", the charter device is considered to be a real innovation by the external evaluation mission. However, the latter considers that "few charters were signed" and that the device "did not live up to its expectations" (Jourdain-Menninger et al., 2010).

Generally speaking, and beyond the external assessment, most of the criticisms made of the device agree on the small number of charters signed ${ }^{12}$. We come back to this point below and provide our own proposal of success indicators for assessment of the device, in a dynamic and interactive perspective of the policy process.

\subsubsection{Another perspective on the indicator "number of charters signed"}

At first glance, 30 charters signed in six years seem a few. In fact, the number of charters signed and the rate at which they were signed cast doubts on the possibility of eventually fulfilling the government's aim that was to "reach a maximum number of operators" (MS, 2006).

However, what are the reference number and the reference period to consider it as "little"? What significance should be given to this indicator within an innovative and experimental

\footnotetext{
${ }^{12}$ For example, we can find this criticism in the discussion of the initiation of actions to improve the offer within the framework of the French National Food Program (PNA), lauched by the Ministry of Agriculture in 2010 (MAAP, 2011).
}

device based on voluntary participation? Is the number of charters signed a relevant indicator for the assessment of the device?

Our interviews revealed that the high level of standards imposed and the means necessary to put together the application package (very time- and labor-intensive and requiring a high level of expertise) could have discouraged certain economic actors from filing an application, particularly small and medium-sized companies that are poorly represented in the device. Nevertheless, this low adherence cannot be considered as an indicator of the lack of interest of EOs for the device. For example, in June 2011, 27 charters were signed, but the number of applications filed at the time was 43 , i.e., $40 \%$ of the approaches proposed were not validated (and among those, some ten were abandoned) ${ }^{13}$.

The official texts of the program do not specify either a measurable objective or a formalized indicator for the assessment of the charter device. The PNNS coordinators interviewed in 2011 said that it is the general objective of the program that should be evaluated.

\subsubsection{Nutritional level of the commitments}

Our analysis of the charters reveals that: the commitments are substantial ${ }^{14}$; the improvements in composition cover all of the eligible nutrients and the proposals meet the requirements concerning the part of the offer covered by the charter. The "proposal-negotiation-validation" process that leads to the signature of a charter seems to have contributed to this result. In this process, the point of departure, crystallized in the initial application, consists of prior knowledge and the constraints of the economic actors (e.g. technological, economic, organoleptic, sanitary). On the basis of this first proposal, a "personalized" negotiation takes place, with several backand-forth discussions possible between the validation committee and the EO. This process acts as a strong filter to ensure that the commitments are accepted when they are significant and realistic. The possibility of proposing commitments "subject to conditions" also encourages the EOs to propose more ambitious commitments since they have the possibility of modifying their content or the level of the initial objective in the future if the motives to justify the change are valid. For example, Orangina-Schweppes, faced with great uncertainty about consumer preferences, is committed to improving the composition of soft drinks without alcohol if the improved products are validated by consumer tests. In this way, the device has contributed to dissuading, filtering or improving poorer quality proposals. The validation committee has in fact been criticized for pushing quality requirements to the extreme by considering that certain proposals to improve composition are insufficient despite the fact that they concern large volumes (Jourdain-Menninger et al., 2010). In the search for a compromise between the level of nutritional quality of a charter (assessed primarily on the basis of improvements in product composition) and the global volumes concerned by

\footnotetext{
${ }^{13}$ Data provided by one of the device's coordinators.

${ }^{14}$ In order to analyze the nutritional level of the commitments, we particularly focused on improvements in the nutritional composition of the products, which is, as we have already seen, the central aspect of the charter device.
} 
Table 3. Impact of commitments made by the signatories at other levels of the production chain and in relation to other actors. Domino effect.

\begin{tabular}{ll}
\hline \multicolumn{1}{c}{ Functions of the production chain or actors concerned } & \multicolumn{1}{c}{ Type of impact } \\
\hline Distribution on processing & $\begin{array}{l}\text { Bid calls followed by specifications - Awareness, information } \\
\text { Source of innovation for suppliers' suppliers (forums) }\end{array}$ \\
Processing on distribution & $\begin{array}{l}\text { Commitments related to national brands have an effect on retailer brands } \\
\text { Type of raw materials required and characteristics of fresh products }\end{array}$ \\
$\begin{array}{l}\text { Processing on processing (processor supplier) } \\
\text { Processing on the restaurant sector }\end{array}$ & $\begin{array}{l}\text { On processed ingredients that are part of the final product } \\
\text { Processing and/or distribution on consumers, health }\end{array}$ \\
Information, training, education, medical advice.
\end{tabular}

professionals, company employees, patients, journalists,

research

improvements, the strategy deliberately chosen by those responsible for the implementation of the device was therefore to give priority to quality aspects.

\subsubsection{Accessibility of improved products}

A study on the potential impact of charters on the French population nutritional intake finds that ultimately all socioeconomic classes will benefit from reformulations and that for all nutrients, except for calcium (Oqali, 2012).

To our knowledge, there has been no quantitative assessment of the impacts of nutritional improvements on product price until now. Our analysis reveals that the promised improvements are distributed across the product range: within a charter, improvements are not reserved just for the high end of the product range. We consider that the inclusion of this criterion as one of the conditions for eligibility of a charter was a determining factor for it to be complied with by each EO. Moreover, we observed that a very small minority of signatories explicitly commit themselves to questions of price. Nevertheless, according to the experts consulted, no price increase is linked to nutritional improvements.

\subsubsection{Fulfilling commitments}

The commitments made by the EOs were fulfilled. The cases where the initial objectives had to be modified by the EOs with the agreement of the validation committee remain exceptional and even anecdotal. This suggests that the flexibility provided by the agreements, e.g., in the form of commitments "subject to condition", can be used correctly and judiciously by the economic actors. The very in-depth assessment of the charters, their public and publicized signature, and the availability of their content on an official site are all factors that may have contributed to the fact that the commitments were fulfilled. This compliance is even more meaningful since no sanction was planned in the case of noncompliance.

\subsubsection{Domino effects that are difficult to assess}

We observed that the commitments included in a charter, whether individual or collective, have an impact on actors other than the charter signatories. We call this the domino effect whose nutritional, economic and social impact should not be neglected. Even if a charter is individual, it mobilizes much more than just the signatory EO. In fact, signatories make commitments that have repercussions on other levels of the production chain and on other actors such as, for example, suppliers of raw materials or processed products that contribute to the composition of the final product (Tab. 3). A particular case is that of the retailer sector for the production of its retailer brands. For example, the Casino group, signatory of a charter, "works today with more than 450 food suppliers of which some are small companies"15. This means of subcontracting on the part of the retailer leads to a multiplier effect of its own nutritional improvement commitments on the manufacturers that produce the retailer brand products concerned by these commitments. It goes hand-in-hand with the role of innovation catalyzer played by the retailer in relation to certain retailer brand suppliers, and particularly small companies. The latter would perhaps not have undertaken nutritional improvement measures if the retailer had not integrated nutritional requirements into the selection criteria of the responses to the bid offers. Finally, in addition to the impacts of the charters on actors other than the signatories, we can also mention real impacts on products developed by the same signatories but not within the scope of the charter. Indeed, for logistical reasons, the commitment to improve a product can lead to improvements of other products of the signatory firm for which no commitment was made.

According to this analysis, to assess the impact of charters, it would first be necessary to situate the charter device in its context in order to define the limits of the system concerned by the impact of improvements.

\subsubsection{Temporality}

How much time is considered reasonable to "reach a maximum number of operators"? Analysis of the charter device reveals a particularly long time frame and a slow time step for the nutritional improvement of the offer. One of the specificities of contractual policies is the integration of a time dimension (Lascoumes et al., 1989). Time is a factor in the preparation of charters, negotiations prior to their validation, in the flexibility that could make it possible to take some variables (price, consumer reactions) into account, in the progress of nutritional improvements, in the research process that underlies innovation, in the idea of emulation between

\footnotetext{
$\overline{\left.{ }^{15} \text { Casino charter (Casino, } 2008\right) .}$
} 
firms, in the changes of consumers' preferences, etc. The mobilization of a contractual and voluntary policy instrument attempts to integrate the approach into a long-term strategy.

\subsubsection{An ambitious device but out of phase with the urgency of expectations}

The lack of experience and the low availability of research on VAs in the area of nutrition may explain why criticism has focused on the number of agreements signed, as if they were considered within the measures of classical regulation. Taking into account the specificities of contractual policies, our extended approach considers other aspects and highlights new impacts of the device, some of which are difficult to measure.

Our interpretation of the charter approach reveals a device which is demanding, in terms of nutritional performance of each commitment, and responsive to questions of accessibility of products targeted by a charter. According to our analysis, the committed actors keep their promises. In addition, this device has effects on other products and other actors rather than those directly concerned by the VAs. It is supposed to contribute to the control of diseases linked to diet, however, given the urgent nature of the problem, its adhesion rate can be considered as too slow. The charter device would therefore address the seriousness of the problem but not its urgency. Admittedly, the device has been integrated into a long-term strategy.

\subsection{What were the limits of the charter policy action model on the offer?}

What were the limits of the model for policy action on the offer set out in the PNNS? Why a model designed to lead to the signature of a large number of collective commitments produced individual agreements instead, with a rate of adherence considered to be inadequate by external reviewers?

Between the "declared policy aspirations" at the root of the model for action and the results obtained, the overlapping is not complete. What are the factors that contributed to this gap? We will mention two of them which are linked to the design of the device as well as to its implementation.

\subsubsection{Poorly adapted incentive}

In order for a company to improve the nutritional quality of its products, the result should be acceptable from the economic point of view. This acceptability can also be the result of indirect effects that a company expects, for example, its integration, through its nutritional improvements, into a sustainable development approach or one of corporate social responsibility, etc. Sanctions or the threat of the establishment of another more limiting policy instrument can also encourage firms to undertake voluntary approaches (David, 2004). Sanctions are absent in the charter device and if the threat of the application of another instrument exists, it is not explicitly laid out and is therefore not totally credible (Segerson and Miceli, 1998; Krarup, 2001).

By giving the possibility of making their commitment public, the government hoped to incite the EOs to improve their standard offer and to reward them for their efforts, considering that if nothing was offered in exchange, they would have no reason to join the device. In fact, some firms explained their refusal to make their commitment public in terms of strategy and the image of their products (consumers could then say: "so, your products were not up to nutritional standards before?") ${ }^{16}$. Several firms found that the commitment was more interesting in relation to legitimizing in-house approaches in progress or to be undertaken, rather than in relation to consumers. Also, the incentive offered by the government seems to be poorly adapted to counteracting the commercial risks incurred by product change. Moreover, this mention may contribute to the consumer's confusion. On the one hand, it is independent of the level of effort involved. On the other hand, as a result of the halo effect (Thorndike, 1920), the consumer can interpret it as a guarantee of good nutritional quality intrinsic to the product and not as a signal of participation in a quality improvement approach. For the same reason, the validation committee experts hesitated to validate a charter in some cases, forgetting "that only nutritional improvement is welcome by the charter, even if it involves products previously considered as 'fatty, salty or sweet" (Jourdain-Menninger et al., 2010). These cases concern foods that, despite the improvements proposed, will always remain too rich in those nutrients whose consumption would be desirable to reduce.

The incentive, in the broadest sense (mentions, sanctions, threats, etc.), must be adapted to the specific situation in which the agreement device will be established and to the aims that underlie these agreements. Also it must be flexible enough to be able to evolve according to changes in global offer quality and in the behavior of offer and demand actors, in particular of signatory firms.

\subsubsection{Shortage of collective approaches}

Few agreements were signed after completion of the work of the thematic groups, and among the small number of collective applications submitted, there were a number of proposals that were not followed up. It should however be mentioned that these groups constitute the only action intended to promote collective commitments within the device. This is probably due to the fact that the collective agreements were introduced into the texts at the request of the Ministry of Agriculture, whereas the Ministry of Health had only provided for individual agreements. In fact, the Ministry of Health, responsible for the implementation of the charter device, counts on emulation and competition. It considers that it is the individual agreements that will make it possible to go further in terms of nutritional improvement. Its position is that signing only collective agreements would mean relinquishing part of the effort that could have been made by some firms within the collective. It considers that the firm that determines the level of collective effort is the one that will make the smallest contribution to improvement. The limit of this reasoning can be found in the organoleptic constraints that can hinder the most ambitious individual approaches, even if they are progressive. When changes in nutritional composition are collective, the risk of an eventual decrease in the interest of consumers for non-improved products is lowered since modifications are more generalized and their progressivity

\footnotetext{
${ }^{16}$ Statement made by a major group, very much involved in the healthy image of its products, which signed a charter.
} 
coordinated. The lack of interest of firms for the collective charters could also be due to the fact that firms do not really need to work together to find solutions to the technical challenges facing them in terms of the improvement of the nutritional quality of their products. They would not be in a situation of shared radical uncertainties (Aggeri et al., 1995) where the synergy of efforts would make it possible to end a deadlock and make better and faster progress. Firms seem to have the means to advance independently in the area of nutrition, and this is even more evident when the diversity of the processes responsible for similar products can be a factor that limits the interest for common and generalized solutions. Moreover, for those firms capable of improving their products, the individual agreement is a means of promoting a competitive asset while maintaining a trade secret. Finally, collective agreements are more difficult to establish than individual agreements because it is necessary to mobilize and coordinate several different entities. If we add the limited efforts intended to promote collective agreements, the absence of a specific guide for collective charters as well as the high level of requirement in relation to the commitments, we can perhaps explain the predominance of individual agreements. This situation raises an essential question: should the government target small, generalized improvement or should it set its stakes on a bigger improvement that only affects a small part of the offer, hoping that, as a result of emulation, the rest of the offer will follow?

\subsection{Charter dilemma: privilege requirement level or adhesion level?}

Modification of the quality of the offer by voluntary nutritional improvement commitments concerns two key dimensions: (1) the quality intrinsic to the commitments; and (2) the share of the global offer covered by signed commitment charters. This latter dimension can be assimilated to the number of agreements signed, even if it may vary depending on the competition structure of the sector and on the individual or collective character of the charter. Interactions between these two dimensions can be illustrated by a diagram with four main quadrants (Fig. 2). They represent as many situations as possible in the commitment process and make it possible to trace the different improvement trajectories of the offer. Section 5 of the diagram represents the part of the offer that is not necessary to modify because it corresponds, for example, to traditional recipes or to festive foods. Taking quadrant 2 as a departure point, the aim of the French charter device is to progressively shift to quadrant 3, i.e., to obtain a large number of commitments, collective or individual, of high nutritional quality. A constant of this trajectory is the high level of requirements in terms of nutrition, as well as for the preparation of the application. This last aspect, far from being negligible, turned out to be an impediment for the submission of applications.

An alternative trajectory (Fig. 2) would have been to target a gradual increase in commitments that were less ambitious in terms of quality in order to obtain a large volume of the offer related to nutritional improvements, even of a limited scope (shift from 1 to 4 ). The second stage of this trajectory would have been the gradual increase of the quality of commitments

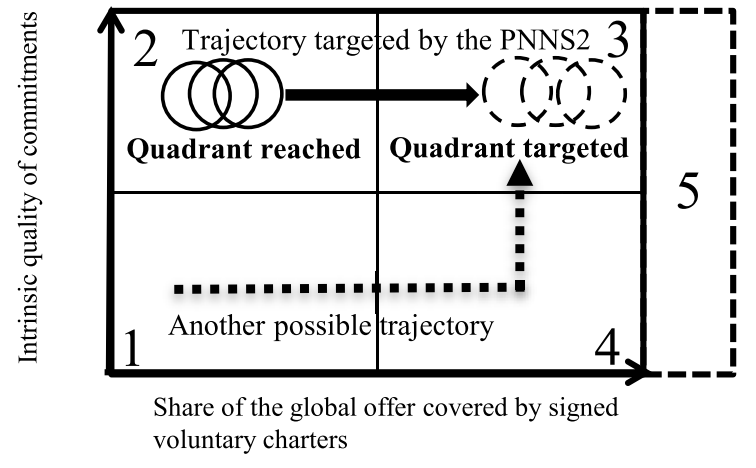

Fig. 2. Possible trajectories for the improvement of the nutritional offer through voluntary commitments. 1 . Small number of commitments with low nutritional quality. 2. Small number of commitments with high nutritional quality. 3. Large number of commitments with high nutritional quality. 4. Large number of commitments with low nutritional quality. 5 . Part of the offer that does not necessarily need to be modified (traditional recipes, festive foods, etc.).

on the part of the EOs, shifting from 4 to 3 or remaining in an intermediate shared position between quadrants 4 and 2 if some of the EOs did not improve the quality of their commitments above a certain level. We could have hoped for this type of trajectory if the signature of the collective charters had been presented to the EOs as a condition for signing more demanding individual charters with a specific mention at a later date. We believe that it is possible that the leading firms could act as a driving force so that their sector could collectively reach a minimum level of improved nutritional quality and sign a collective charter. These leaders would be guided by two motivations. On the one hand, they would want to differentiate themselves by signing more demanding individual charters. In this case, the question still remains as to which incentive should be offered to allow the leaders to distinguish themselves. On the other hand, they would try to avoid any possible negative fallout on the sector's image incurred by the delay in terms of nutritional quality. This ripple effect propagated by the leading firms through professional organizations could also come about through the modification of the "usage code"17 or the creation of an MQS (Minimum Quality Standard). Improvement would then be generalized and perpetuated. It is possible that at the end of this process, the number of potential candidates for the signature of more demanding individual charters would increase since some EOs, initiated despite themselves to the nutritional improvement approach, would perhaps discover a strategic interest. This reasoning nevertheless remains hypothetical.

Reasoning in terms of a trajectory leads to the question of the presence of elements that could act as positive ripple factors of these VAs based on emulation. To illustrate that, we will mention one of them, which can be double-edged in

\footnotetext{
${ }^{17}$ Usage code or code of practice is a non-binding document offering a general framework for recommendations whose purpose is the adoption of uniform measures by the sector to which it is addressed. It contains general recommendations concerning practices and operations that must be implemented in the aim of reaching fixed objectives (Definition of the Food and Agriculture Organization of the United Nations).
} 
practice. The principle of retroactivity to encourage adhesion can be found among the elements that may act as positive ripple factors, particularly in relation to exemplary actions. For example, in the Bleu-Blanc-Cœur charter, the commitment of this association focuses particularly on the breakdown of what it has already accomplished. Should retroactivity be considered as a windfall effect or as a fair public recognition for an effort already made which in turn could be an inspiration to other firms?

This discussion casts light on the difficulties of the public authorities to identify clear signals to be sent to EOs to create positive dynamics within adhesion trajectories.

\section{Conclusions}

The gap observed between the projected policy action model and the implemented program confirms the interest in studying public policies through actions and instruments and not only through projects and announced goals (Lascoumes and Le Galès, 2004; Aggeri and Labatut, 2010).

Our work shows that the instrumental food policy innovation, represented by the charters, must be accompanied by an innovation in the evaluation methods. Evaluating voluntary agreements without taking into account their specific characteristics, the "nature of the problem" (Aggeri, 1999) and the dynamic and interactive perspective of the policy process, does not make it possible to measure their impacts on the whole food system and consequently diminishes the possibilities of making operational feedback.

Our analysis indicates that a VA must not just be considered as an objective in itself but as a contribution to the improvement of the quality of the global offer. As a result, such a device must be thought out in terms of a trajectory, by strategically mobilizing the different resources available. According to the dynamics of this trajectory, we can be led to momentarily favor the volume of the improved offer rather than the quality of the signed commitments (within acceptable limits), giving priority to quality at another stage. The same is true for the choice between the use of individual and/or collective agreements and the most effectively adapted sequence to mobilize them.

The French device appears to be original and rigorous in relation to several points analyzed. In the absence of experiences that could provide reference points which we could refer to, as well as measurable objectives established beforehand, the reference point used to judge the success or failure of the device is the expectations that it generated. These expectations were not fulfilled for many of the actors involved. While taking the specific time frame of this type of instrument into account, we consider that the urgency of health problems linked to diet forces us to reflect on the optimization of the adhesion rate and, particularly, on the increase of collective commitments.

\section{Funding}

This research did not receive any specific grant from the commercial or not-for-profit sectors.
Conflicts of interest. The author declares that she has no conflicts of interest in relation to this article.

\section{Références}

Aggeri F. 1998. Environnement et pilotage de l'innovation: un modèle dynamique du développement durable. Le cas du recyclage automobile. École Nationale Supérieure des Mines de Paris, p. 390.

Aggeri F. 1999. Environmental policies and innovation: A knowledge-based perspective on approaches. Res Policy 28: 699-717.

Aggeri F, Labatut J. 2010. La gestion au prisme de ses instruments. Une analyse généalogique des approches théoriques fondées sur les instruments de gestion. Finance Contrôle Stratégie 13: 5-37.

Aggeri F, Lefebvre P, Hatchuel A. 1995. La naissance de la voiture recyclable: intervention de l'État et apprentissages collectifs. Cahiers de Recherche du Centre Scientifique de Gestion, 80 p.

Allard-Poesi F. 2011. Le codage n'est pas un «truc» méthodologique ou du codage comme «problématisation». Le Libellio d'Aegis 7: 3-8.

Ayache M, Dumez H. 2011. Le codage dans la recherche qualitative une nouvelle perspective? Le Libellio d'Aegis 7: 33-46.

Barde J-P. 1992. Économie et politique de l'environnement. Paris : Presses universitaires de France.

Basdevant A, Bas-Théron F, Combris P, et al. 2006. Obésité : bilan et évaluation des programmes de prévention et de prise en charge. Paris : INSERM Éditions.

Brownell KD, Horgen KB. 2004. Food fight: The inside story of the food industry, America's obesity crisis, and what we can do about it. Chicago: Contemporary Books.

Brownell KD, Kersh R, Ludwig DS, et al. 2010. Personal responsibility and obesity: A constructive approach to a controversial issue. Health Affair 29: 379-387.

Coglianese C. 2001. Is consensus an appropriate basis for regulatory policy?. In: Orts E, Deketelaere K, eds. Environmental contracts: Comparative approaches to regulatory innovation in the United States and Europe. Dordrecht: Kluwer Law International.

Combris P, Goglia R, Henini M, Soler LG, Spiteri M. 2011. Improvement of the nutritional quality of foods as a public health tool. Public Health 125: 717-724.

David M. 2004. Les approches volontaires comme instrument de régulation environnementale. Revue Française d'Economie 19: 227-273.

EC. 1996. Communication from the Commission to the Council and the European Parliament on environmental agreements, COM 96 561. Final, November 27 European Environmental Agency, 1997.

EC. 2002. Environmental Agreements at Community Level Within the Framework of the Action Plan on the Simplification and Improvement of the Regulatory Environment. Communication from the Commission to the European Parliament, the Council, the Economic an Social Committée and the Committee of the Regions. Brussels, 17.7.2002 COM(2002) 412 final.

Eckel RH, Borra S, Lichtenstein AH, Yin-Piazza SY. 2007. Understanding the complexity of trans fatty acid reduction in the American diet. Circulation 115: 2231-2246.

Forgues B, Vandangeon-Derumez I. 2007. Analyses longitudinales. In: Thiétart R-A, ed. Méthodes de recherche en management. Paris : Dunod, pp. 439-465.

Foucault M. 1977. Le jeu de Michel Foucault (entretien). In: Foucault M, ed. Dits et écrits III. Paris : Gallimard. 
Girgis S, Neal B, Prescott J, et al. 2003. A one-quarter reduction in the salt content of bread can be made without detection. Eur J Clin Nutri 57: 616-620.

Glachant M. 1995. Les accords volontaires dans la politique environnementale: une mise en perspective de leur nature et de leur efficacité. In: Economie \& Prévision, Agriculture et environnement 117-118: 49-59. doi: 10.3406/ecop.1995.5713.

Golan E, Unnevehr L. 2008. Food product composition, consumer health, and public policy: Introduction and overview of special section. Food Policy 33: 465-469.

Grolleau G, Mzoughi N, Thiébaut L. 2004. Les instruments volontaires : un nouveau mode de régulation de l'environnement? Revue internationale de droit économique 18: 461-481.

Harris JL, Pomeranz JL, Lobstein T, Brownell KD. 2009. A crisis in the marketplace: How food marketing contributes to childhood obesity and what can be done. Annu Rev Public Health 30: 211-225.

Hatchuel A. 1994. Apprentissages collectifs et activités de conception. Revue Française de Gestion: 109-120.

Hawkes C. 2007. Regulating food marketing to young people worldwide: Trends and policy drivers. Am J Public Health 97: 1962-1973.

Hercberg S, Tallec A. 2000. Pour une politique nutritionnelle de santé publique en France. Paris: La Documentation Française, Haut comité de la santé publique.

Hercberg S, Chat-Yung S, Chauliac M. 2008. The French National Nutrition and Health Program: 2001-2006-2010. Int J Public Health 53: 68-77.

Hervé-Fournereau N. 2008. Les approches volontaires et le droit de l'environnement. Presses Universitaires de Rennes, p. 326.

Highley CJ, Convey F, Leveque F. 2001. Voluntary Approach: An introduction. In: Highley CJ, Leveque F, eds. Concerted action on voluntary approaches. International Policy Workshop on the Use of Voluntary Approach (CAVA). Bruxelles: Centre d'économie industrielle École Nationale Supérieure des Mines de Paris (CERNA), pp. 1-4.

Jourdain-Menninger D, Lignot-Leloup M. 2003. Comparaisons internationales sur la prévention sanitaire. Paris: Inspection Général des Affaires Sociales.

Jourdain-Menninger D, Lecoq G, Guedj J, Boutet P, Danel J-B, Mathieu G. 2010. Évaluation du programme national nutrition santé PNNS2 2006-2010. Paris: La Documentation Française, Inspection Générale des Affaires Sociales, Conseil général de l'alimentation, de l'agriculture et des espaces ruraux.

Kersh R. 2009. The politics of obesity: A current assessment and look ahead. Milbank $Q$ 87: 295-316.

Kersh R, Morone J. 2002. The politics of obesity: Seven steps to government action. Health Affair 21: 142-153.

Kersh R, Morone JA. 2005. Obesity, courts, and the new politics of public health. $J$ Health Polit Polic 30: 839-868.

Krarup S. 2001. Can voluntary approaches be environmentally effective and economically efficient?. In: Higley CJ, Lévêque F, eds. Environmental voluntary approaches: Research insights for policy-makers. Paris : CERNA, pp. 52-64.

Kvale S, Brinkmann S. 2009. Interviews. Learning the craft of qualitative research interviewing, 2 ed. Los Angeles - London New Delhi - Singapour: SAGE.

L'Abbe MR, Stender S, Skeaff CM, Ghafoorunissa Tavella M. 2009. Approaches to removing trans fats from the food supply in industrialized and developing countries. Eur J Clin Nutr 63: S50-S67.

Lang T. 2006. Food, the law and public health: Three models of the relationship. Public Health 120: 30-40.
Lascoumes P. 1994. L'éco-pouvoir. Environnements et politiques. Paris : La Découverte.

Lascoumes P, Le Galès P. 2004. Gouverner par les instruments. Paris : Presses de la Fondation Nationale de Science Politique.

Lascoumes P, Benghozi M, Robert F. 1989. Négocier le droit de l'environnement?: le volet discret d'une politique publique: contrats et programmes de branches, programmes d'entreprises. Première partie, Les négociations et leurs contextes. Politiques et Management Publique 11: 47-83.

Ludwig DS, Nestle M. 2008. Can the food industry play a constructive role in the obesity epidemic? $\mathrm{J} \mathrm{Am} \mathrm{Med} \mathrm{Assoc}$ 300: 1808.

Mancino L, Kuchler F, Leibtag E. 2008. Getting consumers to eat more whole-grains: The role of policy, information, and food manufacturers. Food Policy 33: 489-496.

Menard C, Dumas C, Goglia R, et al. 2011. Oqali: A French database on processed foods. J Food Compos Anal 24, 744-749.

MS, MES. 2012. Les chartes d'engagements de progrès nutritionnels. Ministère de l'emploi et de la solidarité-Ministère délégué à la santé, DGS/Sous-direction EA, Prévention des risques liés à l'environnement et à l'alimentation.

Mzoughi N. 2005. Analyse économique des approches volontaires de régulation de l'environnement. Dijon: Université de Bourgogne, p. 234.

Nestle M. 2002. Food politics: How the food industry influences nutrition and health. Berkeley: University of California Press.

Nijman CAJ, Zijp IM, Sierksma A, et al. 2006. A method to improve the nutritional quality of foods and beverages based on dietary recommendations. Eur J Clin Nutr 61: 461-471.

Oqali. 2012. Évaluation de l'impact potentiel des chartes d'engagements volontaires de progrès nutritionnel sur les apports en nutriments de la population française. Oqali, p. 147

Oqali. 2013. Étude d'impact des chartes d'engagements volontaires de progrès nutritionnel sur les volumes de nutriments mis sur le marché. Étude actualisée, Édition 2013. Oqali, p. 66.

Pettigrew AM. 1990. Longitudinal field research on change: Theory and practice. Organ Sci 1: 267-292.

Pomeranz JL, Brownell KD. 2008. Legal and public health considerations affecting the success, reach, and impact of menu-labeling laws. Am J Public Health 98: 1578-1583.

Pomeranz JL, Teret SP, Sugarman SD, Rutkow L, Brownell KD. 2009. Innovative legal approaches to address obesity. Milbank $Q$ 87: 185-213.

Ratnayake WMN, L'Abbe MR, Farnworth S, et al. 2009. Trans fatty acids: Current contents in Canadian foods and estimated intake levels for the Canadian population. J AOAC Int 92: 1258-1276.

Ricciuto L, Lin K, Tarasuk V. 2009. A comparison of the fat composition and prices of margarines between 2002 and 2006, when new Canadian labelling regulations came into effect. Public Health Nutr 12: 1270-1275.

Romelaer P. 2005. L'entretien de recherche. In: Roussel P, Wacheux F, eds. Management des ressources humaines. Méthodes de recherche en sciences humaines et sociales. Bruxelles: De Boeck, pp. 101-137.

Rossman GB, Rallis SF. 1998. Learning in the field: An introduction to qualitative research. Thousand Oaks, CA: Sage.

Saunders D, Jones S, Devane GJ, Scholes P, Lake RJ, Paulin SM. 2008. Trans fatty acids in the New Zealand food supply. J Food Compos Anal 21: 320-325.

Sebillotte C. 2016. Nutrition et bien commun. La construction d'un nouveau modèle d'action publique. Thèse de doctorat de l'Université de recherche Paris Sciences et Lettres PSL Research University préparée à Mines ParisTech, p. 547. 
Sebillotte M, Sebillotte C. 2002. Recherche finalisée, organisations et prospective. La méthode prospective SYSPAHMM (Système, Processus, Agrégats d'Hypothèses, Micro et Macroscénarios). OCL 9(5): 329-345.

Sebillotte M, Sebillotte C. 2010. Foresight in mission-oriented research: The SYSPAHMM foresight method (SYStem, Processes, Clusters of Hypotheses, Micro-and Macroscenarios). Futures 42: 15-25.

Segerson K, Miceli TJ. 1998. Voluntary environmental agreements: Good or bad news for environmental protection? J Environ Econ Manag 36: 109-130.

Seiders K, Petty RD. 2004. Obesity and the role of food marketing: A policy analysis of issues and remedies. J Public Policy Mark 23: 153-169.

Sharma LL, Teret SP, Brownell KD. 2010. The food industry and selfregulation: Standards to promote success and to avoid public health failures. Am J Public Health 100: 240-246.

Stanley F, Daube M. 2009. Should industry care for children? Public health advocacy and law in Australia. Public Health 123: 283-286.

Swinburn B, Egger G, Raza F. 1999. Dissecting obesogenic environments: The development and application of a framework for identifying and prioritizing environmental interventions for obesity. Prev Med 29: 563-570.

Thomson BM. 2009. Nutritional modelling: Distributions of salt intake from processed foods in New Zealand. Br J Nutr 102: 757-767.

Thorndike EL. 1920. A constant error in psychological ratings. $J$ Appl Psychol 41: 25-29.

Unnevehr LJ, Jagmanaite E. 2008. Getting rid of trans fats in the US diet: Policies, incentives and progress. Food Policy 33: 497-503.

Wilde P. 2009. Self-regulation and the response to concerns about food and beverage marketing to children in the United States. Nutr Rev 67: 155-166.
Yach D, Khan M, Bradley D, Hargrove R, Kehoe S, Mensah G. 2010. The role and challenges of the food industry in addressing chronic disease. Global Health 6(1): 10.

\section{Web references}

Casino. 2008. Groupe Casino, Charte d'engagements volontaires de progrès nutritionnel dans le cadre du programme national nutrition santé II. http://solidarites-sante.gouv.fr/IMG/pdf/ casino.pdf (accessed 23.11.2017).

MAAP. 2011. Le Programme National pour l'Alimentation (PNA). Ministère de l'agriculture, de l'alimentation, de la pêche, de la ruralité et de l'aménagement du territoire, $75 \mathrm{p}$. http://agriculture. gouv.fr/sites/minagri/files/documents/pdf/PNA-09022011.pdf.

MAAP, MINEFI, MS, 2007. Référentiel type pour les chartes d'engagements volontaires de progrès nutritionnel proposées par les exploitants du secteur alimentaire dans le cadre du programme national nutrition santé 2 . Ministères en charge de l'agriculture, de la consommation et de la santé, Paris, 13 p. http://agriculture. gouv.fr/telecharger/44202?token=24726a77588a2d7564a9e3055 d8e9df0 (accessed 23.11.2017).

MS. 2006. Deuxième Programme National Nutrition-Santé PNNS 2006-2010, Actions et mesures. Ministère de l'emploi et de la solidarité-Ministère délégué à la santé, p. 51. https://www.irbms. com/download/documents/programme-national-nutrition-santepnns-2006-2010.pdf (accessed 23.11.2017).

MS. 2017. Les signataires des chartes d'engagements de progrès nutritionnels. Ministère des solidarités et de la Santé. http:// solidarites-sante.gouv.fr/prevention-en-sante/preserver-sasante/le-programme-national-nutrition-sante/article/les-signatai res-des-chartes-d-engagements-de-progres-nutritionnels (accessed 23.11.2017).

Citation de l'article : Sebillotte C. 2019. Efficiency of public-private co-regulation in the food sector: the French voluntary agreements for nutritional improvements. OCL 26: 34. 